\title{
Light-Microscopy-Based Sparse Neural Circuit Reconstruction: Array Tomography and Other Methods
}

\author{
*Correspondence to: \\ Rah JC, \\ Tel: +82-53-980-8350 \\ Fax: +82-53-980-8339 \\ E-mail: jcrah@kbri.re.kr \\ Received December 21, 2016 \\ Revised December 23, 2016 \\ Accepted December 23, 2016
}

\author{
Jong-Cheol Rah* \\ Korea Brain Research Institute, Laboratory of Neurophysiology, Daegu 41062, Korea
}

.

.


resolution of this technique is determined by the thickness of the section instead of by Abbe's rule. Synapses can be resolved with approximately $80 \%$ accuracy by AT compared to TEM (Rah, 2013). Multiple axonal origins can be distinctively labeled using different fluorescent proteins, which articulate the origins of the synapses. Since every voxel of the tissue has the same chance of antibody labeling, the molecular identity of the synapses can be examined in a quantitative manner. Moreover, antibody staining on thin sections can be easily removed and the sections can then be restained. Repeated cycles of antibody staining and stripping allows for detailed investigation of the proteomic diversity of synapses of interest (Micheva et al., 2010). Gathering the necessary information about a neural circuit from AT images is relatively simple because of high contrast and isotropic resolution. In terms of imaging area, AT is applicable to a sufficiently large volume of brain tissue to cover entire cortical layers (Rah, 2013) or hippocampal CA1 pyramidal neurons (Bloss et al., 2016).

However, circuit reconstruction with AT is a rather fragile and laborious process that involves handling 100-nm thick serial sections. On top of that, a synapse detection accuracy of $80 \%$ may be enough for some biological questions, but certainly not for all. In the following sections, I review the pros and cons of other imaging techniques for studying neural circuits. Selective-plane illumination microscopy (SPIM) is now widely used for efficient optical sectioning because of its high-contrast with reduced photo damage. The volume of reconstruction can be limited by the working distance of the lens. For that reason, conventional SPIM is more commonly used with brain clearing methods for area-toarea connectivity reconstruction where the observation of cell bodies and bundles is sufficient (Tomer et al., 2015, but see Cella Zanacchi et al., 2011).

Many super-resolution microscopy techniques now also provide improved axial resolution. For instance, with interferometric photoactivated localization microscopy (iPALM), three-dimensional stochastic optical reconstruction microscopy (3D-STORM), one can acquire better axial and lateral resolution than one can possibly slice without the hassle of laborious serial sectioning (Huang et al., 2008; Shtengel et al., 2009). A potential drawback of these techniques is the severe limitations in depth and field-of-view. The use of selective fluorophores and slow imaging speeds also require improvement before these techniques can be used for largevolume circuit reconstruction. It is important to remember that imaging thick specimens with high axial resolution is accompanied by antibody penetration issues. Clever sample preparation followed by conventional microscopy provides a good alternative for this issue. GRASP or green fluorescent protein (GFP) Reconstitution Across Synaptic Partners utilizes overexpressed GFP-fusions of interacting presynapse- and postsynapse-specific proteins (Feinberg et al., 2008; Kim et al., 2011). Although there are concerns about the synaptogenic feature of overexpressed synaptic proteins (Graf et al., 2004; Scheiffele et al., 2000), the number of synapses as well as the subcellular localization of synapses were in agreement with previous studies at least in gross level (Kim et al., 2011). Expansion microscopy uses the physical expansion of a polymer network that is covalently anchored to a specific location within the specimen (Chen et al., 2015, 2016). Considering the expansion factor of the specimen, an effective resolution of approximately $70 \mathrm{~nm}$ lateral and 200 $\mathrm{nm}$ axial could be achieved even with conventional confocal microscopy. There is no obvious evidence that this technique affects the overall structure of neurons, which would suggest uneven expansion or distortion of the neuronal structure.

The methods described above and other techniques may be perfectly adequate for testing some hypotheses but none of them is a magic bullet. The combination of these technologies would lead to a powerful tool for large-volume neural circuit

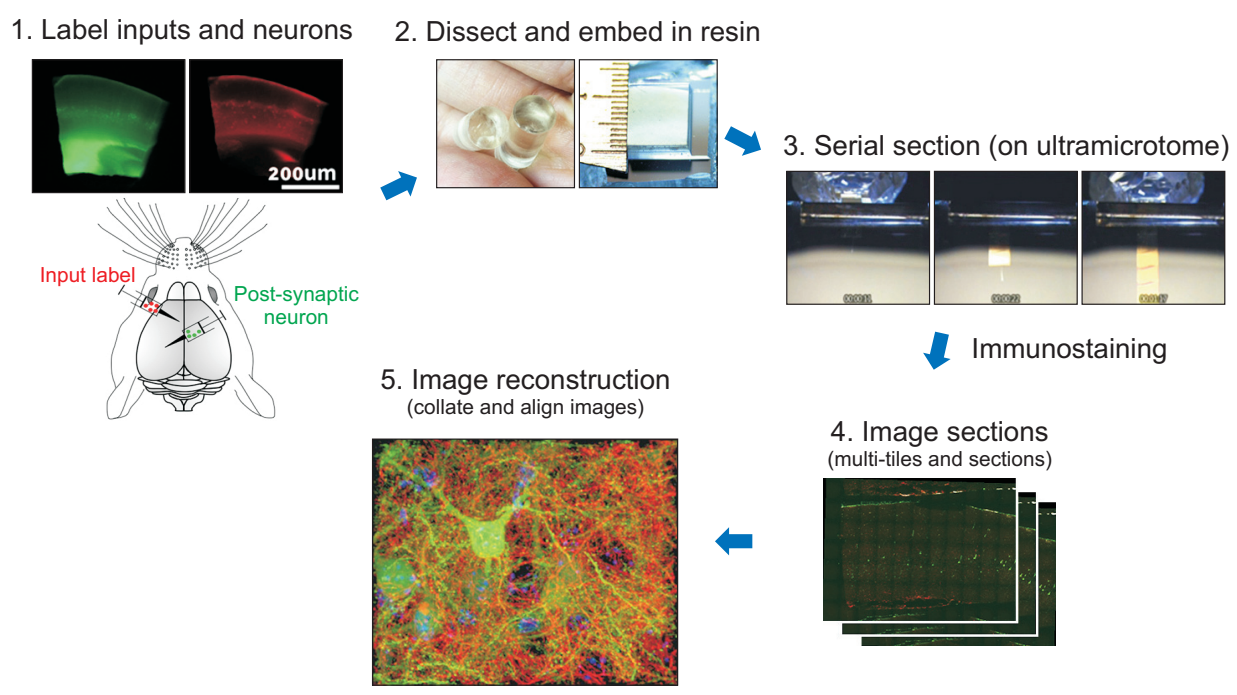

Fig. 1. Schematic diagram of the array tomography. 
reconstruction (Nanguneri et al., 2012; Punge et al., 2008; Sigal et al., 2015).

\section{CONFLICT OF INTEREST}

No potential conflict of interest relevant to this article was reported.

\section{ACKNOWLEDGMENTS}

This study was supported by the KBRI Program (2231$415)$ and the Basic Science Research Program (NRF2014R1A1A2057804).

\section{REFERENCES}

Bloss E B, Cembrowski M S, Karsh B, Colonell J, Fetter R D, and Spruston N (2016) Structured dendritic inhibition supports branch- selective integration in CA1 pyramidal cells. Neuron 89, 1016-1030.

Bock D D, Lee W C A, Kerlin A M, Andermann M L, Hood G, Wetzel A W, Yurgenson S, Soucy E R, Kim H S, and Reid R C (2011) Network anatomy and in vivo physiology of visual cortical neurons. Nature 471, 177-182.

Briggman K L, Helmstaedter M, and Denk W (2011) Wiring specificity in the direction-selectivity circuit of the retina. Nature 471, 183-188.

Cella Zanacchi F, Lavagnino Z, Perrone Donnorso M, Del Bue A, Furia L, Faretta M, and Diaspro A (2011) Live-cell 3D super-resolution imaging in thick biological samples. Nat. Meth. 8, 1047-1049.

Chen F, Tillberg P W, and Boyden E S (2015) Optical imaging. Expansion microscopy. Science 347, 543-548.

Chen F, Wassie A T, Cote A J, Sinha A, Alon S, Asano S, Daugharthy E R, Chang J B, Marblestone A, Church G M, Raj A, and Boyden E S (2016). Nanoscale imaging of RNA with expansion microscopy. Nature Methods 13, 679-684.

DeFelipe J, Marco P, Busturia I, and Merchán-Pérez A (1999) Estimation of the number of synapses in the cerebral cortex: methodological considerations. Cerebral Cortex 9, 722-732.

Feinberg E H, VanHoven M K, Bendesky A, Wang G, Fetter R D, Shen K, and Bargmann C I (2008) GFP reconstitution across synaptic partners (GRASP) defines cell contacts and synapses in living nervous systems. Neuron 57, 353-363.

Graf E R, Zhang X, Jin S X, Linhoff M W, and Craig A M (2004) Neurexins induce differentiation of GABA and glutamate postsynaptic specializations via neuroligins. Cell 119, 1013-1026.

Hayworth K J, Kasthuri N, Schalek R, and Lichtman J W (2006) Automating the collection of ultrathin serial sections for large volume TEM reconstructions. Microsc. Microanal. 12, 86-87.

Huang B, Wang W, Bates M, and Zhuang X (2008). Three-dimensional super-resolution imaging by stochastic optical reconstruction microscopy. Science 319, 810-813.

Kim J, Zhao T, Petralia R S, Yu Y, Peng H, Myers E, and Magee J C (2011) mGRASP enables mapping mammalian synaptic connectivity with light microscopy. Nat. Meth. 9, 96-102.

Lee W C A, Bonin V, Reed M, Graham B J, Hood G, Glattfelder K, and Reid R C (2016) Anatomy and function of an excitatory network in the visual cortex. Nature 532, 370-374.
Micheva K D, Busse B, Weiler N C, O'Rourke N, and Smith S J (2010) Single-synapse analysis of a diverse synapse population: proteomic imaging methods and markers. Neuron 68, 639-653.

Micheva K D and Smith S J (2007) Array tomography: a new tool for imaging the molecular architecture and ultrastructure of neural circuits. Neuron 55, 25-36.

Mikula S, Binding J, and Denk W (2012) Staining and embedding the whole mouse brain for electron microscopy. Nat. Meth. 9, 11981201.

Mishchenko Y (2010) On optical detection of densely labeled synapses in neuropil and mapping connectivity with combinatorially multiplexed fluorescent synaptic markers. PLoS One 5, e8853.

Morgan J L, Berger D R, Wetzel A W, and Lichtman J W (2016) The fuzzy logic of network connectivity in mouse visual thalamus. Cell $\mathbf{1 6 5}$, 192-206.

Nanguneri S, Flottmann B, Horstmann H, Heilemann M, and Kuner T (2012). Three-dimensional, tomographic super-resolution fluorescence imaging of serially sectioned thick samples. PLoS One $\mathbf{7}$, e38098.

Punge A, Rizzoli S O, Jahn R, Wildanger J D, Meyer L, Schönle A, Kastrup L, and Hell S W (2008) 3D reconstruction of high-resolution STED microscope images. Microsc. Res. Tech. 71, 644-650.

Rah J C (2013) Thalamocortical input onto layer 5 pyramidal neurons measured using quantitative large-scale array tomography. Front. Neural Circuits 7, 177.

Scheiffele P, Fan J, Choin J, Fetter R, and Serafini T (2000) Neuroligin expressed in nonneuronal cells triggers presynaptic development in contacting axons. Cell 101, 657-669.

Shtengel G, Galbraith J A, Galbraith C G, Lippincott-Schwartz J, Gillette J M, Manley S, Sougrat R, Waterman C M, Kanchanawong P, Davidson M W, Fetter R D, and Hess H F (2009) Interferometric fluorescent superresolution microscopy resolves $3 \mathrm{D}$ cellular ultrastructure. Proc. Natl. Acad. Sci. U.S.A. 106, 3125-3130.

Sigal Y M, Speer C M, Babcock H P, and Zhuang X (2015) Mapping synaptic input fields of neurons with super-resolution imaging. Cell 163, 493-505.

Tomer R, Lovett-Barron M, Kauvar I, Andalman A, Burns V M, Sankaran S, Grosenick L, Broxton M, Yang S, and Deisseroth K (2015) SPED light sheet microscopy: fast mapping of biological system structure and function. Cell 163, 1796-1806. 